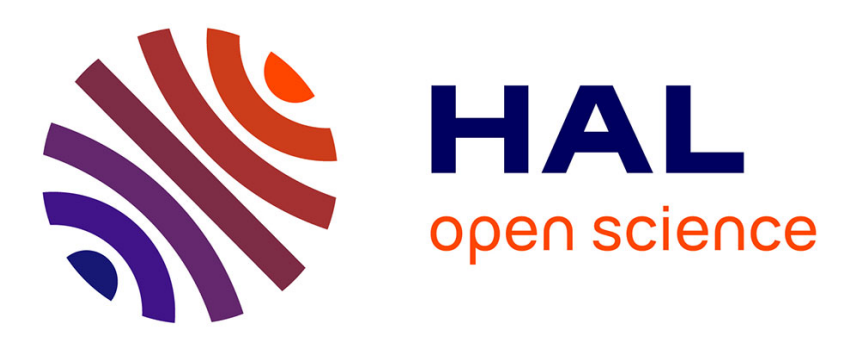

\title{
GRANULOCYTE-COLONY STIMULATING FACTOR ENHANCES BONE FRACTURE HEALING
}

Didier Moukoko, Didier Pourquier, Cécile Genovesio, Simon Thèzenas, Patrick Chabrand, Sandrine Roffino, Martine Pithioux

\section{- To cite this version:}

Didier Moukoko, Didier Pourquier, Cécile Genovesio, Simon Thèzenas, Patrick Chabrand, et al.. GRANULOCYTE-COLONY STIMULATING FACTOR ENHANCES BONE FRACTURE HEALING. Clinical Biomechanics, 2018. hal-01844236

\section{HAL Id: hal-01844236 https://hal.science/hal-01844236}

Submitted on 31 Jul 2018

HAL is a multi-disciplinary open access archive for the deposit and dissemination of scientific research documents, whether they are published or not. The documents may come from teaching and research institutions in France or abroad, or from public or private research centers.
L'archive ouverte pluridisciplinaire HAL, est destinée au dépôt et à la diffusion de documents scientifiques de niveau recherche, publiés ou non, émanant des établissements d'enseignement et de recherche français ou étrangers, des laboratoires publics ou privés. 
1 Title: GRANULOCYTE-COLONY STIMULATING FACTOR ENHANCES BONE

2 FRACTURE HEALING

4 Didier MOUKOKO $^{1}$, Didier POURQUIER ${ }^{2}$, Cécile GENOVESIO ${ }^{3}$, Simon THEZENAS ${ }^{4}$,

5 Patrick CHABRAND ${ }^{5,6}$, Sandrine ROFFINO ${ }^{5,7=}$, Martine PITHIOUX ${ }^{5,6=}$.

6

$7 \quad{ }^{1}$ Département de Chirurgie Orthopédique Pédiatrique, CHU Angers 4 rue Larrey 49100 Angers,

8 France.

$9 \quad{ }^{2}$ Laboratoire de Pathologie, ICM Val d'Aurelle, 208 rue des Apothicaires, 34298 Montpellier

10 cedex 5, France.

$11{ }^{3}$ Laboratoire de Biochimie, Faculté de Pharmacie, 27 Boulevard Jean Moulin. 13005 Marseille,

12 France.

$13{ }^{4}$ Unité de Biostatistiques, ICM Val d'Aurelle, 208 rue des Apothicaires, 34298 Montpellier

14 Cedex 5, France.

$15{ }^{5}$ Aix Marseille Univ, CNRS, ISM, Inst Movement Sci, Marseille, France.

$16{ }^{6}$ APHM, Hôpital Sainte Marguerite, IML, Marseille, France.

$17{ }^{7}$ Université Côte d'Azur, Univ Nice Sophia Antipolis.

18 = equal contribution

19

20 Corresponding author : martine.pithioux@ univ-amu.fr.

21 Words counts abstract : 250

22 Words counts article : 3915 


\section{Abstract}

\section{Background}

26 Circulating mesenchymal stem cells contribute to bone repair. Their incorporation in fracture

27 callus is correlated to their bioavailability. In addition, Granulocyte-colony stimulating factor

28 induces the release of vascular and mesenchymal progenitors. We hypothesized that this

29 glycoprotein stimulates fracture healing, and analyzed the effects of its administration at low

30 doses on bone healing.

31 Methods

3227 adult male Sprague-Dawley rats underwent mid-femur osteotomy stabilized by centromedullar

33 pinning. In a post (pre) operative group, rats were subcutaneously injected with $5 \mu \mathrm{g} / \mathrm{kg}$ per day of

34 Granulocyte-colony stimulating factor for 5 days after (before) surgery. In a control group, rats

35 were injected with saline solution for 5 days immediately after surgery. A radiographic

36 consolidation score was calculated. At day 35 , femurs were studied histologically and underwent

37 biomechanical tests.

38 Findings

395 weeks after surgery, mean radiographic scores were significantly higher in the Preop group

407.75 (SD 0.42) and in the Postop group 7.67 (SD 0.52) than in the control group 6.75 (SD 0.69).

41 Biomechanical tests showed femur stiffness to be more than three times higher in both the Preop

$42109.24 \mathrm{~N} / \mathrm{mm}$ (SD 51.86) and Postop groups 100.05N/mm (SD 60.24) than in control

$43 \quad 32.01 \mathrm{~N} / \mathrm{mm}$ (SD 15.78). Mean maximal failure force was twice as high in the Preop group 68.66

$44 \mathrm{~N}$ (SD 27.78) as in the control group 34.21N (SD 11.79). Histological results indicated a later

45 consolidation process in control than in treated groups.

46 Interpretation 
47 Granulocyte-colony stimulating factor injections strongly stimulated early femur fracture healing,

48 indicating its potential utility in human clinical situations such as programmed osteotomy and

49 fracture.

50 Keywords : Three-point-bending test, Fracture healing, Granulocyte-colony stimulating factor,

51 Circulating mesenchymal progenitor cells, Histology

52 


\section{Introduction}

54 Fracture consolidation has long been considered a locoregional process involving mesenchymal

55 progenitor cells derived from the tissues damaged by the trauma (local bone marrow, endosteum,

56 bone tissue, periosteum, muscles). Following a series of cellular and molecular event cascades

57 reminiscent of the embryonic stages of skeletal tissue formation, these cell precursors lead to the

58 regeneration of the initially injured tissue. However, the 2000s saw the discovery of circulating

59 osteoprogenitor cells (Kuznetsov et al., 2001; Labat et al., 2000), now known to contribute to the

60 bone formation and repair process (Otsuru et al., 2007; Otsuru et al., 2008). In physiologic state,

61 these cells represent 1 to $2 \%$ of circulating mononuclear cells in adults and nearly $10 \%$ in

62 adolescents (Eghbali-Fatourechi et al., 2005). They increase in response to osteogenic

63 requirements: in animals, during an ectopic osteogenesis process, they can transiently rise to $80 \%$

64 of circulating mononuclear cells (Otsuru et al., 2008). This cell pool can contribute up to $10 \%$ of

65 the osteoblasts present in a fracture consolidation callus (Kumagai et al., 2008) and as much as

$6650 \%$ of the osteocytes present in an ectopic bone regenerate (Otsuru et al., 2008).

67 Intravenous injections of blood-derived osteoprogenitor cells stimulate fracture repair (Granero-

68 Molto et al., 2009; Wan et al., 2006). Their rate of incorporation into the callus increases

69 proportionally to their serum bioavailability, until it reaches a plateau. Beyond this value, it

70 remains stable regardless of increases in serum level (Granero-Molto et al., 2009). On the other

71 hand, endogenous circulating osteoprogenitor cell bioavailability can be transiently boosted by

72 the pharmacological use of bioactive molecules that trigger the mobilization of their medullary

73 precursors, thereby favoring bone repair (Kumar et al., 2012; Matsumoto et al., 2008; Toupadakis

74 et al., 2013). 
76 G-CSF is a glycoprotein used in human therapeutics for its ability to mobilize medullary

77 hematopoietic stem cells in systemic circulation. G-CSF also induces the mobilization of vascular

78 stem cells (Minamino et al., 2005) and mesenchymal stem cells (Levesque et al., 2007; Tatsumi

79 et al., 2008; Zhdanov et al., 2007), both of which are involved, to varying degrees, in skeletal

80 tissue repair. In rats, there was a significant increase in $\mathrm{CD} 34^{+}$progenitor cells after five

81 consecutive injections of G-CSF (Herrmann et al., 2018). These cells are capable of

82 differentiating into osteogenic as well as vasculogenic lineages (Sidney et al., 2014).

83 Surprisingly, few studies have been published on the use of G-CSF as a skeletal tissue repair or

84 regeneration adjuvant (Kaygusuz et al., 2006; Wu et al., 2008). When administered topically, G-

85 CSF improves neovascularization and osteogenesis, which leads to regeneration of both critical-

86 size bone defects in a rabbit bone resection model (Ishida et al., 2010) and tendon graft in a

87 ligamentoplasty model (Sasaki et al., 2008). When administered parenterally, G-CSF

88 counterbalances the negative effects of NSAIDs on bone healing, probably by stimulating

89 osteogenesis (Kaygusuz et al., 2006). In a rabbit femoral osteonecrosis model, the combined use

90 of G-CSF and Stem Cell Factor cause increased osteoblast activity and improve local

91 revascularization, leading to more effective regeneration of the necrotic bone tissue volume (Wu

92 et al., 2008).

93 To date, only two studies have focused on the effects of parenteral administration of G-CSF on

94 fracture healing (Bozlar et al., 2005; Herrmann et al., 2018), both finding that G-CSF accelerated

95 bone repair in rats. However, the doses used in these studies were respectively 2.5 (Bozlar et al.,

96 2005) and 5 times higher (Herrmann et al., 2018) than the recommended dose in human clinical

97 practice with healthy subjects. In fact, for donors providing peripheral blood stem cells for

98 recipients of hematopoietic stem cell transplants, recombinant human G-CSF is generally

99 recommended at a dose of $10 \mu \mathrm{g} / \mathrm{kg}$ per day. Even at this dose, side effects are observed, although 
100 when the dose is reduced, the side effects decrease (Lambertini et al., 2014). Furthermore, Bozlar

101 et al. (2005) and Herrmann et al. (2018) chose to work only on emergency clinical applications

102 (e.g fractures, large defects) and did not consider programmed clinical applications (e.g bone

103 lengthening, tumor removal).

104 In this work, from a perspective of the eventual therapeutic use of GCSF in humans, we

105 investigated the effects of parenteral administration of a $5 \mu \mathrm{g} / \mathrm{kg}$ per day dose of G-CSF on

106 fracture consolidation in rats. We also investigated G-CSF administration pre-surgery vs G-CSF

107 administration post-surgery. Pre-surgery administration mirrors the human clinical situation of a

108 programmed osteotomy, and post-surgery administration mirrors a fracture situation.

109

110 


\section{$111 \quad$ Materials and Methods}

112 Twenty-seven male Sprague Dawley rats (OFA), weighing 500g and twelve weeks old at time of

113 surgery were used in the experiment. The animals were fed a standard diet ad libitum. They were

114 housed singly in cages in temperature-controlled rooms $\left(22^{\circ} \mathrm{C}\right)$ having a $12 \mathrm{~h}$ light cycle. All

115 animal protocols were approved by the University of Aix-Marseille institutional animal care and

116 use committee and the French research ministry (authorization number 02572.02), and performed

117 in the conventional animal house of Marseille Medical Faculty (France).

\section{$119 \quad 2.1$ Surgical protocol}

120 The surgical model consisted of right femur mid-diaphyseal osteotomy, immediately

121 osteosynthesized by centromedullary pinning. Under general anesthesia consisting of

122 intraperitoneal Ketamine $75 \mathrm{mg} / \mathrm{kg}$ and Medetomidine $0.15 \mathrm{mg} / \mathrm{kg}$ and under strictly aseptic

123 conditions, the right femur was exposed via a lateral subperiosteal approach. Medial-diaphyseal

124 osteotomy was performed using piezotome. Retrograde centromedullary pinning ( 2 mm diameter

125 Kirschner wires) was performed by lateral parapatellar arthrotomy. The muscular fascia was

126 closed with separated resorbable stitches and the skin with slow-absorption continuous stitches.

127 Postoperative analgesia and prophylactic antibiotic therapy consisted of an injection of

128 Buprenorphine $0.05 \mathrm{mg} / \mathrm{kg}$ and subcutaneous Baytril $10 \mathrm{mg} / \mathrm{kg}$ peroperatively, then once per day

129 for 3 days. Rats were followed weekly by radio to check that they were healthy.

\section{$131 \quad 2.2$ Experimental groups}


132 Rats were randomized to one of three distinct pharmacological procedures. The "Postoperative"

133 group (Postop) with 9 rats were injected subcutaneously with $5 \mu \mathrm{g} / \mathrm{kg}$ per day of G-CSF

134 (FILGRASTIM) for 5 days starting from surgery. The "Preoperative" group (Preop) with 9 rats

135 received identical G-CSF injections for 5 days preoperatively. In the Control group, 9 rats were

136 injected subcutaneously for 5 days with a saline solution, starting immediately after surgery.

137 One rat died in the control group upon induction of anesthesia. One rat died in the Postop group

138 being found dead one day after surgery. One rat in the Preop group was sacrificed three days after

139 surgery due to splitting of the scar tissue. No locoregional infections or other complications were

140 observed in the other animals. After 35 days of consolidation, the animals were sacrificed by

141 intraperitoneal lethal injections of Sodium Pentobarbital $100 \mathrm{mg} / \mathrm{kg}$.

\section{$143 \quad 2.3$ Radiographic analysis}

144 X-rays of the femurs subjected to surgery were taken immediately postoperatively, then at days 7 ,

14521 under general anesthesia and at day 35 after the sacrifice. A radiographic consolidation score

146 (An et al., 1999) was calculated from the analysis of the X-rays by two orthopedic surgeons not

147 involved in the study (Table 1) and who analyzed independently each x-ray according to the

148 radiographic scoring system for fracture healing (An et al., 1999). The final score assigned to

149 each x-ray was the mean of the scores of the two surgeons.

152 Table 1: Radiographic scoring system for fracture healing (An et al., 1999) .

\begin{tabular}{|l|l|}
\hline CATEGORY & SCORE \\
\hline Periosteal reaction & \\
\hline
\end{tabular}




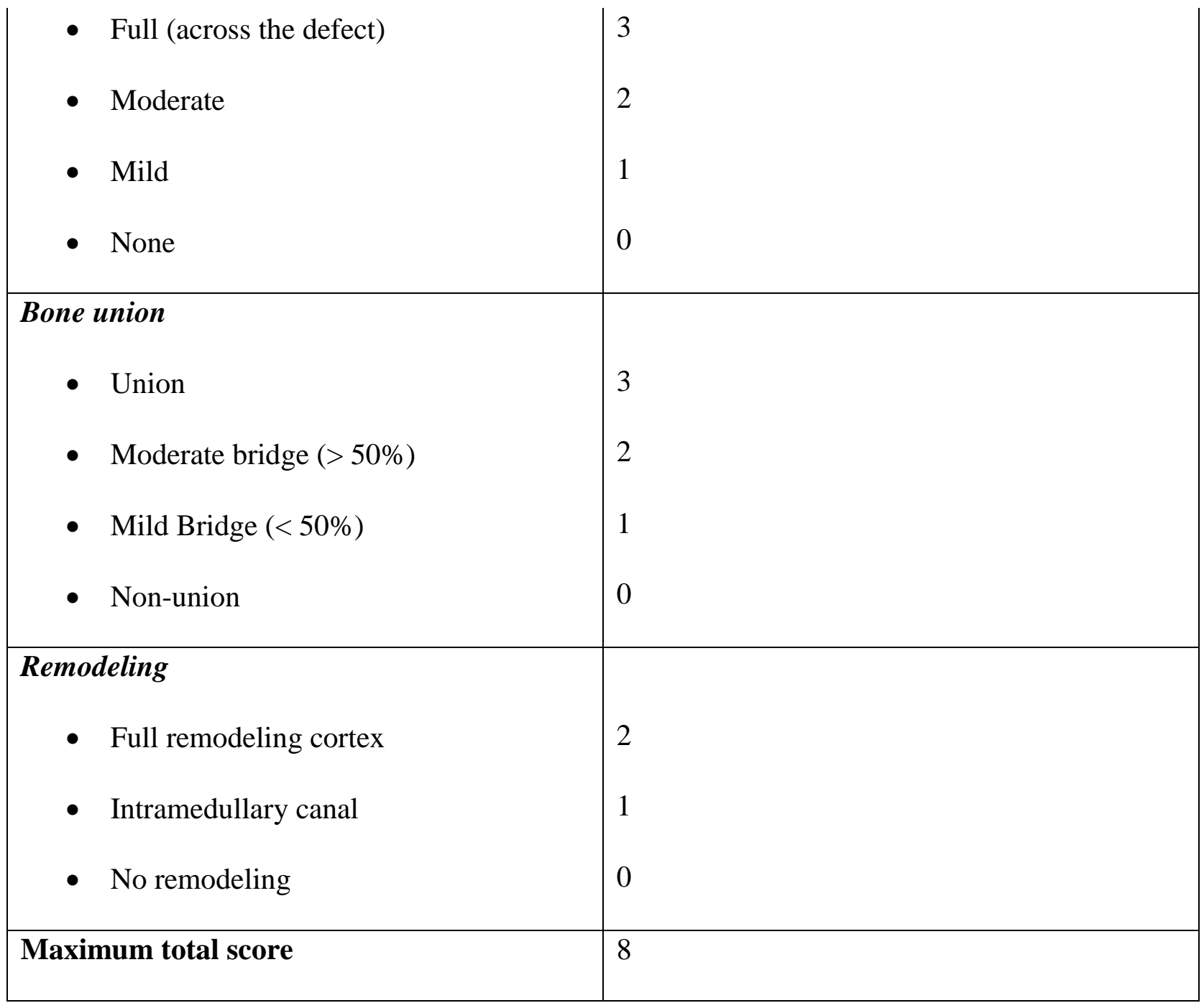

\section{$154 \quad 2.4$ Mechanical analysis}

155 Femurs subjected to surgery (6 femurs from control group, 6 femurs from Preop group and 6 156 from Postop group) and healthy contralateral femurs ( 6 femurs from control group, 6 femurs from

157 Preop group and 6 from Postop group) underwent destructive mechanical tests. The fixation pin 158 and soft tissue were completely removed before tests.

159 The fresh material was frozen and stored at $-20^{\circ} \mathrm{C}$, which does not alter the structure or properties 160 of bone. The samples were slowly thawed at room temperature before preparation and 161 mechanically tested under three-point-bending (Turner et al., 1993) on a testing device (MTS 162 Instron 5566A, INSTRONC Elancourt, France, 1000N load with an accuracy of 0.19\%). We 163 used preconditioning at $1 \mathrm{~N}$ and subsequently imposed a speed of $0.5 \mathrm{~mm}$ per min. 
164 Force/displacement curves were obtained. Failure force and stiffness of the fracture site were 165 analyzed.

\section{$167 \quad 2.5$ Histological analysis}

168 Six femurs subjected to surgery underwent histological analysis after 35 days of consolidation (2

169 from control group, 2 from Postop group, 2 from Preop group). The fixation pin was removed

170 and the fracture site was isolated from the femur and fixed in 4\% formaldehyde (Merk Millipore)

171 in $0.01 \mathrm{M}$ phosphate buffer saline (Sigma-Aldrich) at $\mathrm{pH} 7.4$ for one week. Following fixation,

172 tissue samples were washed with deionized water and were dehydrated through an ethanol

173 gradient of $60 \%, 80 \%, 95 \%, 100 \%$ ethanol, each step lasting 48 hours. Samples were cleared in

174 methylcyclohexan (VWR international) for 48h before infiltration and embedding in Methyl

175 methacrylate (MMA) resin (VWR international). Samples then underwent polymerization in a

$17628^{\circ} \mathrm{C}$ water bath for 3 days.

177 After trimming of the blocks, $5 \mu \mathrm{m}$ thick longitudinal sections were obtained using a microtome

178 (Leica@ RM 2265, Wetzlar, Germany) equipped with a D-profile tungsten-carbide knife. The

179 sections were transferred to Superfrost Plus slides and stretched with $70 \%$ ethanol. Slides were

180 covered with a plastic film, pressed and dried for 2 days. Before staining, MMA was removed

181 from the sections by immersion in three changes of 2-methoxyethylacetate (Merk Millipore) for

182 20min each, one change of ethanol 70 for $5 \mathrm{~min}$, one change of ethanol 40 for $5 \mathrm{~min}$, and then

183 rehydrated in two deionized water baths. The sections were stained with toluidine blue and Von

184 Kossa. They were dehydrated and mounted using a resinous mounting medium (Entellan, Merk

185 Millipore).

186

\section{$187 \quad$ 2.6 Statistical analyses}


188 Due to the small size of the groups, we chose to use nonparametric tests. The nonparametric

189 Kruskal-Wallis test was used to compare consolidation scores for the three groups (control,

190 Preop, Postop) at each time point (J7, J21, J35). This same test was used to compare stiffness and

191 failure force values for the three groups, both for the contralateral femurs and for the femurs

192 subjected to surgery. The significance level was set at $\mathrm{p}<0.05$. For the multiple comparisons, we

193 used the Conover-Iman test with a Bonferroni correction. Statistical analysis was performed

194 using XLSTAT software.

195

196

2. Results

197

\subsection{Radiographic results}

198 Radiographic consolidation scores for all time points are presented in table 2. In the peripheral

199 callus, asymmetrically distributed around the fracture site, signs of mineralization were visible

200 from 7 days after surgery. At days 7 and 21, a significant difference was observed between the

201 control group and the Postop group alone $(\mathrm{p}=0.001$ at day $7 ; \mathrm{p}=0.001$ at day 21$)$. At day 35 , we

202 observed a significant difference between the control group and the Preop group $(p=0.008)$ as

203 well as between the control group and the Postop group $(\mathrm{p}=0.013)$. At this date, the osteotomy

204 site remained visible on all femurs, pointing to incomplete remodeling. At each time point, the

205 difference between the two treated groups was not significant $(p=0.094$ at day $7 ; p=0.046$ at

206 day $21 ; \mathrm{p}=0.806$ at day 35$)$.

207

208 Table 2 : Radiographic score

\begin{tabular}{|l|l|l|l|}
\hline & Control group & Preop group & Postop group \\
\hline
\end{tabular}




\begin{tabular}{|l|l|l|l|}
\hline $\mathrm{D}+7$ postop & $0.75(0.27)$ & $1.50(0.84)$ & $2.33(1.13)^{*}$ \\
\hline $\mathrm{D}+21$ post op & $3.83(0.82)$ & $4.83(0.75)$ & $5.75(0.82) *$ \\
\hline $\mathrm{D}+35$ postop & $6.75(0.69)$ & $7.75(0.42) *$ & $7.67(0.52)^{*}$ \\
\hline
\end{tabular}

Values are Mean (SD). D: day of surgery. * Significant by comparison with the control group.

\section{$211 \quad 3.2$ Mechanical results}

2125 weeks after surgery, force/displacement curves were obtained for 18 healed femurs from the

213 three experimental groups and for 18 control femurs obtained from their contralateral femurs.

214 Although the femurs systematically fractured at the level of the bony callus during the 3-point

215 bending tests, two types of failure profile were observed. The control group femurs experienced

216 ductile failure, while the preop and postop groups femurs experienced brittle failure, like the

217 contralateral group femurs (Figure 1). The contralateral femurs did not display any significant

218 difference in mean stiffness $(p=0.24)$ or in maximum failure force $(p=0.17)$, irrespective of

219 origin (control, Preop and Postop). Comparing the 3 experimental groups via the Kruskall-Wallis

220 test, we found a significant difference in stiffness $(\mathrm{p}=0.011)$ and maximal failure force $(\mathrm{p}=$

221 0.024). Concerning stiffness, the multiple comparisons showed that the control group

222 significantly differed both from the Preop group $(\mathrm{p}=0.002)$ and from the Postop group $(\mathrm{p}=$

223 0.003). Mean callus stiffness was slightly more than three times higher in the Preop 109.24

$224 \mathrm{~N} / \mathrm{mm}$ (SD 51.86) and in the Postop groups 100.05 N/mm (SD 60.24) than in the control group

$22532.01 \mathrm{~N} / \mathrm{mm}(\mathrm{SD} 15.78)$.

226 Concerning maximal failure force, the multiple comparisons showed that the control group 227 significantly differed from the Preop group $(\mathrm{p}=0.004)$ but no difference from the Postop group 228 was observed $(\mathrm{p}=0.053)$. Mean maximal failure force was twice as high in the Preop group $22968.66 \mathrm{~N}$ (SD 27.78) as in the control group 34.21N (SD 11.79). No significant difference was 
230 observed between Preop and Postop groups neither for stiffness $(\mathrm{p}=0.884)$ nor for failure force $231 \quad(\mathrm{p}=0.217)$.

234 Table 3. Mechanical results.

\begin{tabular}{|l|l|l|l|l|}
\hline & \multicolumn{2}{|c|}{ Contralateral Femurs } & \multicolumn{2}{c|}{ Operated femurs } \\
\hline & Stiffness (N/mm) & $\begin{array}{c}\text { Max failure force } \\
(\mathrm{N})\end{array}$ & Stiffness (N/mm) & Max failure force \\
& & & & $(\mathrm{N})$ \\
\hline Control Group & $327.03(16.71)$ & $191.38(27.96)$ & $32.01(15.78)$ & $34.21(11.79)$ \\
\hline Preop Group & $380.75(123.20)$ & $169.53(28.65)$ & $109.24(51.86)^{*}$ & $68.66(27.78) *$ \\
\hline Postop Group & $386.19(61.65)$ & $169.14(19.20)$ & $100.05(60.24) *$ & $51.65(16.75)$ \\
\hline
\end{tabular}

Values are Mean (SD). * Significant by comparison with the control group.

\section{$238 \quad 3.3$ Histological results}

239 In the control group, a fibrous tissue joined the two cortices, while incomplete bony union was

240 observed in the periosteal callus (Fig 2a). The latter was composed of centrally located

241 uncalcified and calcified cartilage adjacent to newly woven bone, indicating endochondral

242 ossification (Fig 3a). At the periphery, the periosteal callus consisted of woven and lamellar bone

243 (Fig 2a).

244 No difference was observed between the Preop and the Postop G-CSF-treated groups. Neither of

245 the groups showed any evidence of endochondral ossification. There was complete bony union.

246 The osteotomy gap was filled with anastomosed bone trabeculae in the periosteal region of the

247 callus (Figs $2 \mathrm{~b}$ and $2 \mathrm{c}$ ) as well as between the cortices (Fig $3 \mathrm{~b}$ ). In the internal and periosteal 
248 calluses, signs of bone formation and bone resorption indicated that remodeling of regenerated

249 bone was occurring. Bone trabeculae showed on their surface osteoid tissue apposed to rows of

250 osteoblasts and osteoclasts that resorbed bone (Fig 4).

\section{Discussion and conclusion}

253 The concomitant mobilization of angiogenic (Minamino et al., 2005) and mesenchymal stem

254 cells (Wan et al., 2006; Levesque et al., 2007; Tatsumi et al., 2008) by G-CSF suggests its

255 potential contribution to skeletal tissue repair. The purpose of this study was to evaluate the effect

256 of low doses of G-CSF on the consolidation processes in fractures treated by open surgery,

257 mirroring two human clinical situations: programmed osteotomy (Preop group) and fracture

258 (Postop group). Our study showed that a $5 \mu \mathrm{g} / \mathrm{kg}$ per day dose is sufficient to stimulate fracture

259 repair processes. Five weeks after surgery, femurs from both treatment groups showed

260 stimulation of osteotomy site consolidation stemming from systemic G-CSF administration. The

261 efficacy of G-CSF in improving bone repair process was previously demonstrated at higher doses

262 in rats, by Herrmann et al. (2018) and Bozlar et al. (2005). In the latter study, in a rat model of

263 tibia fracture, the authors observed a 10-fold increase in callus mechanical strength three weeks

264 after surgery in animals treated with a $25 \mu \mathrm{g} / \mathrm{kg}$ per day G-CSF injection. In our study, maximal

265 failure force was twice as high in the Preop group as in the control group, and callus stiffness

266 slightly more than tripled in both G-CSF groups compared to control. Since our mean failure

267 force values obtained on healthy bone were similar to those reported in the literature for rats of

268 the same genetic origin, age and sex (Utvåg et al., 1998a; Utvåg et al., 1998b, Utvåg et al., 2001),

269 methodological issues can be excluded. The difference in mechanical values is probably related

270 to the dose of G-CSF administered. Moreover, we did not observe any impairment of 
271 biomechanical behavior in the femurs not subjected to surgery, even though prolonged medullary

272 progenitor cell mobilization is known to lead to deterioration of bone tissue (Wu et al., 2008;

273 Toupadakis et al., 2012). This result is not surprising in view of the short period of injection with

274 G-CSF.

275 Histological analysis corroborated the biomechanical results. In G-CSF treated animals, we

276 observed the complete replacement of endochondral cartilage by bone trabeculae, evidence that

277 the process of remodeling is underway. In the control group animals, however, we observed the

278 persistence of cartilaginous tissue in the process of ossification, which indicates a later

279 consolidation process than in the treated group. The difference between control group and treated

280 groups in terms of tissue type within the callus probably explains why ductile failure was

281 observed in the control animals' bone and brittle failure in animals treated with G-CSF.

282 In human clinical practice, G-CSF is administered both to patients with chronic neutropenia or

283 cancer and to donors providing peripheral blood stem cells for recipients of hematopoietic stem

284 cell transplants. In healthy donors, G-CSF is recommended at the dose of $10 \mu \mathrm{g} / \mathrm{kg}$ administered

285 once daily, and although well tolerated, it induces side effects. In a large prospective study,

286 Pulsipher et al. (2014) reported that some rare life-threatening events occurred after G-CSF

287 administration in healthy donors and that no fatalities occurred. In addition, treated donors

288 showed no evidence of increased risk for cancer, autoimmune illness and stroke. The most

289 common adverse event associated with G-CSF administration in healthy donors is bone and

290 musculoskeletal pain (Lambertini et al., 2014; Tigue et al., 2007). To prevent and treat this pain,

291 nonsteroidal anti-inflammatory agents are commonly used as a first-line treatment, and dose

292 reductions are considered as second-line therapy (Lambertini et al., 2014). Thus, with a view to

293 using G-CSF treatment as a fracture repair adjuvant in humans, we chose to test a low dose of G-

294 CSF. 
295 Our therapeutic approach, derived from regenerative medicine, is founded on the well-

296 documented contribution from circulating progenitor cells to many tissue repair processes.

297 Stimulation of bone repair processes is related to the increased bioavailability of circulating

298 vascular and mesenchymal progenitor cells at the neo-osteogenesis site (Kumar et al., 2012;

299 Matsumoto et al., 2008; Toupadakis et al., 2013; Pignolo et al., 2011). Their incorporation into

300 the skeletal tissue repair site contributes to many steps in the cascade of cellular and molecular

301 events of the endochondral osteogenesis processes. During initial stages, these cells modulate the

302 local and systemic inflammatory response (Iguchi et al., 1991) and induce local emission of

303 cytokines such as BMP-2 that initiate bone tissue repair processes (Granero-Molto et al., 2009).

304 During a later phase, vascular invasion of the cartilage matrix is promoted by angiogenesis and

305 vasculogenesis mechanisms. The latter are supported by the influx and proliferation of circulating

306 angiogenic progenitor cells of medullary origin (Matsumoto et al., 2008; Minamino et al., 2005),

307 which depend on their serum level (Lee et al., 2008). This neoangiogenesis allows the influx of

308 circulating osteogenic progenitor cells, which are incorporated into the callus undergoing

309 ossification. Their incorporation is also dependent upon their serum level (Granero-Molto et al.,

310 2009). Now, according to Herrmann et al. (2016), the bioavailability of vascular and osteogenic

311 progenitor cells such as CD34+ significantly increased after five consecutive injections of G-CSF

312 in rats. In addition, in patients with femoral and tibial nonunion, it has been observed

313 radiographically that fracture healing improved when G-CSF-mobilized CD34+ cells were

314 transplanted to non-union sites (Kuroda et al., 2014). Thus, the stimulation of fracture repair by

315 systemically administered G-CSF observed in our study could result from G-CSF-induced

316 medullary mobilization of vascular and mesenchymal progenitor cells in the vascular

317 compartment, leading to increased incorporation at the tissue repair site. Nevertheless, the

318 possibility that G-CSF improves consolidation by other mechanisms cannot be ruled out. Froberg 
319 et al. (1999) showed that G-CSF induces an increase in blood markers of bone formation such as

320 osteocalcin and bone-specific alkaline phosphatase, which suggests that G-CSF stimulates

321 osteoblastic activity. In addition, the effects of G-CSF could also be related to an increase in

322 some cytokines. In an in vitro model, Kaygusuz et al. (2006) showed that G-CSF, while raising

323 the TGF $\beta_{1}$, has a positive effect on fracture healing and Czekanska et al. (2014) that stimulation

324 of mesenchymal stem cells by G-CSF results in an upregulation of mRNA expression of BMP2,

325 which is involved in bone formation.

326 The rate of incorporation of circulating progenitor cells into the fracture callus is time- and dose-

327 dependent (Granero-Molto et al., 2009). These cells can interact both qualitatively and

328 quantitatively at various stages and times in the osteogenesis process (Iguchi et al., 1991; Lee et

329 al., 2008). We therefore modulated the bioavailability peak of circulating progenitor cells in order

330 to make it overlap with various times and stages in the bone consolidation process.

331 We compared two different chronological sequences, one in which the adjuvant treatment

332 preceded the surgical procedure and one in which it followed the surgery. Five weeks after

333 surgery, no significant difference was observed between the Preop and the Postop groups, neither

334 in callus mechanical behavior nor in the biological structure of the regenerated bone at the

335 fracture site. However, mechanical tests are structural analysis, so we have no information about

336 the callus undergoing ossification and its microstructure. Yet the mechanical characteristics of the

337 callus are governed by its morphology, volume and material characteristics, in particular its

338 degree of mineralization and remodeling. Moreover, only the consolidation score of the Postop

339 group differs from that of the control group at days 7 and 21, indicating potential differences in

340 degree of mineralization between the two treated groups. This difference in consolidation score

341 disappears at day 35. This suggests that, despite the similar radiological profile and mechanical

342 behavior of the explants from the two treated groups observed five weeks after surgery, the 
343 pharmacological effect of G-CSF may have stimulated different stages in the endochondral

344 ossification process.

345 During skeletal tissue regeneration, systemic cell mechanisms participate in tissue repair.

346 Medullary mesenchymal and vascular progenitor cells are mobilized in systemic circulation, then

347 captured at the tissue repair site, where they participate in the various stages of the cellular and

348 molecular events leading to the restoration of injured tissue (Kuroda et al., 2014). G-CSF

349 increases the bioavailability of these circulating progenitor cells. However, we measured neither

350 the kinetics, nor the intensity of blood mobilization of progenitor cells. The correlation between

351 the pharmacological increase in progenitor cell bioavailability and fracture repair stages will be

352 studied in future experimental work. It would be of interest to reevaluate treatment duration and

353 starting time for G-CSF injections relative to the biological phases of the endochondral

354 osteogenesis process. Finally, the stimulation mediated by G-CSF can be considered either in

355 terms of consolidation speed and functional recovery, or in terms of final fracture site strength. In

356 the present study, we chose to study the radiographical, mechanical and histological

357 characteristics of the callus before completion of consolidation and bone remodeling. It would be

358 interesting to follow consolidation callus kinetics to completion. This would reveal whether the

359 final consolidation product is obtained earlier, and whether it is mechanically more efficient in

360 the G-CSF treated groups than in the control group after callus remodeling. Despite its

361 limitations, this study demonstrates that a low-dose, short-term systemic G-CSF adjuvant

362 treatment stimulates fracture repair, indicating its potential utility in human clinical situations

363 such as programmed osteotomy and fracture. The therapeutic modalities of this emerging

364 "regenerative medicine" strategy remain to be determined. 


\section{Acknowledgements}

370 We are grateful to the staff responsible for the care of the rats in accordance with the French

371 ethics committee. We thank Marylène Lallemand and Flavy Roseren for their excellent technical

372 assistance. We thank Marjorie Sweetko for English language revision of the manuscript. 


\section{Reference}

376 An YH, Friedman RJ, Draughn RA. Animal models of fracture or osteotomy. In: An YH,

377 Friedman RJ, CRC press. Animal models in orthopaedic research. 1999. pp 197-217.

378 Bozlar M, Aslan B, Kalaci A, Baktiroglu L, Yanat AN, Tasci A. Effects of human granulocyte-

379 colony stimulating factor on fracture healing in rats. Saudi Med J. 2005; 26:1250-4.

380 Czekanska EM, Ralphs JR, Alini M, Stoddart MJ. Enhancing inflammatory and chemotactic

381 signals to regulate bone regeneration. Eur Cell Mater. 2014;28:320-334.

382 Eghbali-Fatourechi GZ, Lamsam J, Fraser D, Nagel D, Riggs BL, Khosla S. Circulating

383 osteoblast-lineage cells in humans. N Engl J Med. 2005 ;352: 1959-1966.

384 Froberg MK, Garg UC, Stroncek DF, Geis M, McCullough J, Brown DM. Changes in serum

385 osteocalcin and bone-specific alkaline phosphatase are associated with bone pain in donors

386 receiving granulocyte-colony-stimulating factor for peripheral blood stem and progenitor cell

387 collection. Transfusion. 1999;39(4): 410-4.

388 Granero-Molto F, Weis JA, Miga MI, Landis B, Myers TJ, O'Rear L, et al. Regenerative effects

389 of transplanted mesenchymal stem cells in fracture healing. Stem Cells. 2009;27: 1887-1898.

390 Herrmann M, Zeiter S, Eberli U, Hildebrand M, Camenisch K, Menzel U, et al. Five Days

391 Granulocyte Colony-Stimulating Factor Treatment Increases Bone Formation and Reduces Gap

392 Size of a Rat Segmental Bone Defect: A Pilot Study. Front Bioeng Biotechnol. 2018; Feb 12;6:5.

393 Iguchi K, Inoue S, Kumar A. Effect of recombinant human granulocyte colony-stimulating factor

394 administration in normal and experimentally infected newborn rats. Exp Hematol. 1991;19: 352-

3958. 
396 Ishida K, Matsumoto T, Sasaki K, Mifune Y, Tei K, Kubo S, et al. Bone regeneration properties

397 of granulocyte colony-stimulating factor via neovascularization and osteogenesis. Tissue Eng

398 Part A. 2010;16: 3271-3284.

399 Kaygusuz MA, Turan CC, Aydin NE, Temel I, Firat S, Bulut T, et al. The effects of G-CSF and 400 naproxen sodium on the serum TGF-beta1 level and fracture healing in rat tibias. Life Sci.

$401 \quad 2006 ; 80: 67-73$.

402 Kumagai K, Vasanji A, Drazba JA, Butler RS, Muschler GF. Circulating cells with osteogenic

403 potential are physiologically mobilized into the fracture healing site in the parabiotic mice model.

$404 \quad J$ Orthop Res. 2008;26: 165-175.

405 Kumar S, Ponnazhagan S. Mobilization of bone marrow mesenchymal stem cells in vivo

406 augments bone healing in a mouse model of segmental bone defect. Bone. 2012 ;50: 1012-8.

407 Kuroda R, Matsumoto T, Niikura T, Kawakami Y, Fukui T, Lee SY et al. Local transplantation

408 of granulocyte colony stimulating factor-mobilized CD34+ cells for patients with femoral and

409 tibial nonunion: pilot clinical trial. Stem Cells Transl Med. 2014;3(1): 128-34.

410 Kuroda Y, Dezawa M. Mesenchymal stem cells and their subpopulation, pluripotent muscle cells,

411 in basic research and regenerative medicine. Anat Rec (Hoboken). 2014;297: 98-11

412 Kuznetsov SA, Mankani MH, Gronthos S, Bianco P, Robey PG. Circulating skeletal stem cells. J

413 Cell Biol. 2001;153: 1133-1140.

414 Labat ML, Milhaud G, Pouchelet M, Boireau P. On the track of a human circulating

415 mesenchymal stem cell of neural crest origin. Biomed Pharmacother. 2000;54: 146-162.

416 Lambertini M, Del Mastro L, Bellodi A, Pronzato P. The five "Ws" for bone pain due to the

417 administration of granulocyte-colony stimulating factors (G-CSFs). Crit Rev Oncol Hematol.

$418 \quad 2014 ; 89(1): 112-128$. 
419 Lee DY, Cho TJ, Kim JA, Lee HR, Yoo WJ, Chung CY, et al. Mobilization of endothelial

420 progenitor cells in fracture healing and distraction osteogenesis. Bone. 2008;42: 932-941.

421 Levesque JP, Winkler IG, Larsen SR, Rasko JE. 2007. Mobilization of bone marrow-derived

422 progenitors. Handb Exp Pharmacol. 2007;180: 3-36.

423 Matsumoto T, Kuroda R, Mifune Y, Kawamoto A, Shoji T, Miwa M, et al. Circulating

424 endothelial/skeletal progenitor cells for bone regeneration and healing. Bone. 2008;43: 434-9.

425 Minamino K, Adachi Y, Okigaki M, Ito H, Togawa Y, Fujita K, et al. Macrophage colony-

426 stimulating factor (M-CSF), as well as granulocyte colony-stimulating factor (G-CSF),

427 accelerates neovascularization. Stem Cells. 2005;23: 347-354.

428 Otsuru S, Tamai K, Yamazaki T, Yoshikawa H, Kaneda Y. Bone marrow-derived osteoblast

429 progenitor cells in circulating blood contribute to ectopic bone formation in mice. Biochem

430 Biophys Res Commun. 2007;354: 453-48.

431 Otsuru S, Tamai K, Yamazaki T, Yoshikawa H, Kaneda Y. Circulating bone marrow-derived

432 osteoblast progenitor cells are recruited to the bone-forming site by the CXCR4/stromal cell-

433 derived factor-1 pathway. Stem Cells. 2008;26: 223-234.

434 Pignolo RJ, Kassem M. Circulating osteogenic cells: implications for injury, repair, and 435 regeneration. J Bone Miner Res. 2011;26: 1685-1693.

436 Pulsipher MA, Chitphakdithai P, Logan BR, Navarro WH, Levine JE, Miller JP et al. Lower risk

437 for serious adverse events and no increased risk for cancer after PBSC vs BM donation. Blood. $438 \quad 2014 ; 123(23): 3655-63$.

439 Sasaki K, Kuroda R, Ishida K, Kubo S, Matsumoto T, Mifune Y, et al. Enhancement of tendon440 bone osteointegration of anterior cruciate ligament graft using granulocyte colony-stimulating 441 factor. Am J Sports Med. 2008;36: 1519-1527. 
442 Sidney LE, Branch MJ, Dunphy SE, Dua HS, Hopkinson A. Concise review: evidence for CD34

443 as a common marker for diverse progenitors. Stem Cells. 2014;32(6):1380-9.

444 Tatsumi K, Otani H, Sato D, Enoki C, Iwasaka T, Imamura H, et al. Granulocyte-colony

445 stimulating factor increases donor mesenchymal stem cells in bone marrow and their

446 mobilization into peripheral circulation but does not repair dystrophic heart after bone marrow

447 transplantation. Circ J. 2008;72: 1351-8.

448 Tigue CC, McKoy JM, Evens AM, Trifilio SM, Tallman MS, Bennett CL. Granulocyte-colony

449 stimulating factor administration to healthy individuals and persons with chronic neutropenia or

450 cancer: an overview of safety considerations from the Research on Adverse Drug Events and

451 Reports project. Bone Marrow Transplant. 2007; 40: 185-192.

452 Toupadakis CA, Granick JL, Sagy M, Wong A, Ghassemi E, Chung DJ, et al. Mobilization of

453 endogenous stem cell populations enhances fracture healing in a murine femoral fracture model.

454 Cytotherapy. 2013;15: 1136-1147.

455 Toupadakis CA, Wong A, Genetos DC, Chung DJ, Murugesh D, Anderson MJ, et al. Long-term 456 administration of AMD3100, an antagonist of SDF-1/CXCR4 signaling, alters fracture repair. J

457 Orthop Res. 2012;30: 1853-9.

458 Turner CH, Burr DB. Basic biomechanical measurements of bone: a tutorial. Bone. 1993;14:

$459 \quad 595-608$.

460 Utvåg SE, Grundnes $\mathrm{O}$, Reikerås $\mathrm{O}$, Graded exchange reaming and nailing of non-unions.

461 Strength and mineralisation in rat femoral bone, Arch Orthop Trauma Surg. 1998;118: 1-6.

462 Utvåg SE, Korsnes L, Rindal DB, Reikerås O. Influence of flexible nailing in the later phase of

463 fracture healing: strength and mineralization in rat femora, J Orthop Sci. 2001;6: 576-584.

464 Utvåg SE, Reikerås O. Effects of nail rigidity on fracture healing. Strength and mineralisation in 465 rat femoral bone, Arch Orthop Trauma Surg. 1998;118: 7-13. 
466 Wan C, He Q, Li G. Allogenic peripheral blood derived mesenchymal stem cells (MSCs)

467 enhance bone regeneration in rabbit ulna critical-sized bone defect model. J Orthop Res. 2006;24:

$468 \quad 610-8$.

469 Wu YD, Chien CH, Chao YJ, Hamrick MW, Hill WD, Yu JC, et al. Granulocyte colony-

470 stimulating factor administration alters femoral biomechanical properties in C57BL/6 mice. $\mathrm{J}$

471 Biomed Mater Res A. 2008;87: 972-9.

472 Wu X, Yang S, Duan D, Liu X, Zhang Y, Wang J, et al. A combination of granulocyte colony-

473 stimulating factor and stem cell factor ameliorates steroid-associated osteonecrosis in rabbits. J

474 Rheumatol. 2008;35: 2241-8.

475 Zhdanov VV, Stavrova LA, Dygai AM, Goldberg ED. Mechanism of mobilization of

476 mesenchymal stem cell under the effect of granulocyte colony-stimulating factor. Bull Exp Biol

477 Med. 2007;144: 151-3.

478 
481 Fig 1. Examples of force/displacement curves for femurs from the control, preop, postop 482 groups and for contralateral femurs.

Fig 2. Low magnification of the fracture calluses 5 weeks after the osteotomy in control (a), preop (b) and postop group (c). Sections were stained with Von Kossa and counterstained with toluidine blue. (a) Note the fibrous tissue $(*)$ between the cortices (C). Near the site of the osteotomy, the periosteal callus (P) is composed of bony and cartilaginous tissue. (b et c) Bony bridge (arrowheads) joins the fractured ends in the internal and in the periosteal callus regions.

489 Scale bar $2 \mathrm{~mm}$.

492 from the control group (a) and from the Postop group (b) 5 weeks after osteotomy. (a) Around the 493 fracture gap, the reparative process occurs by endochondral ossification. New bone formation

494 (arrow). Capillary invasion (*). Hypertrophic chondrocyte embedded in calcified cartilage

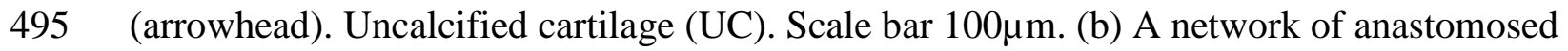
496 trabeculae (arrows) is observed between the cortices (C). In this specimen, trabeculae are 497 composed mainly of mature bone. Scale bar $500 \mu \mathrm{m}$.

499 Fig 4: Micrograph of section stained with toluidine blue from the postop group 5 weeks after 500 osteotomy. On either side of bone trabeculae, the osteoclasts (arrowheads) and osteoblasts that 501 deposit the osteoid (arrows) are observed. Scale bar 50 $\mu \mathrm{m}$. 
503 